\title{
Consultant jobs in mental handicap: dead end posts?
}

\author{
B. N. Nwulu, Consultant Psychiatrist, Beechcroft Unit, District General Hospital, \\ Rotherham, South Yorkshire
}

"That is unusual." "What?" "That young men like you take up consultant posts in mental handicap. I thought it was a job retired psychiatrists returned to, to avoid the boredom of inactivity."

That was a 55 year old consultant psychiatrist to his newly appointed colleague, at lunch.

In the sixties, retired psychiatrists outnumbered other consultants in many mental handicap hospitals. Re-appointed as locums or associate specialists, their posts were renewed annually until Parkinsonism, senility or other illness intervened, forcing the last retirement.

Had these re-appointed, retired consultants job satisfaction? As a junior doctor, I was very impressed with one such consultant, but his case conferences lacked therapeutic and rehabilitative plans. "There is not much you can do for these people. The important thing is to keep them clean and comfortable." Behaviour modification, training and monitoring had little place in his formulation. But although the job fulfilled some of his needs, one of them may not have been job satisfaction.

But then, what of other groups of seniors and consultants in mental handicap, how do they get job satisfaction?

Professors and the university lecturers with honorary consultant posts in mental handicap usually create university departments of mental handicap. Confined to special interest groups, in practice, they research and publish on broadly based issues in the field of mental handicap. On a visit to one professorial unit, a 20 bedded unit that specialises in the assessment and treatment of the mentally impaired, I was impressed with the high nurse-patient ratio. Senior house officers, registrars and senior registrars under the professor reviewed their handful of patients regularly. These trainees rarely concern themselves with the rest of the hospital where 500 patients live, institutionalised. One consultant psychiatrist, one associate specialist and one part-time general practitioner care for them. But the whole hospital has a renown, thanks to the small unit, the professorial unit.

Another small group of contented consultants share jobs in two specialities, usually mental handicap with child psychiatry. Mental handicap with general psychiatry or forensic psychiatry is another option. The trend is popular, judging by the number of consultants in mental handicap, consultants con- tracted full time, and who hunt a shared job. Maybe one sub-speciality makes up for what the other lacks.

We come now to the vast majority of consultants in mental handicap, consultants who are neither in the university departments nor in shared posts. Neither are they re-appointed, retired consultants. Have they job satisfaction, these consultants? This question is not trivial if you consider the mounting medical unemployment and the many vacant consultant posts in mental handicap services in many Regions. Support from peer group relationships, membership of the management group, the opportunity to up-date and to pass on knowledge, the opportunity to practise one's skills: these I think, make for job satisfaction-apart from financial remuneration and job stability. How do these factors influence consultants in mental handicap?

Single consultant posts rarely galvanise support from peer groups. It is common to see one consultant only in a mental handicap service for a District of over 500,000; this in spite of the recommendation of the Royal College of Psychiatrists that consultants should be appointed for between 200,000 and 250,000 of the population. Frozen consultant posts, insistence on the workload rather than the size of the population as the basis for future consultant appointments, uncertainty about the future of the mental handicap service-these strengthen the isolation.

Many mental handicap hospitals are not part of a teaching hospital, and as such are not recognised for training purposes even when they are seven to 20 miles away from the 'centre of excellence'. Cast outside a teaching hospital, deprived of junior medical support, the consultant in mental handicap has no opportunity to pass on knowledge to trainees. Help in the treatment of physical illness is proffered by general practitioners who use their lunch-time break to hurry through selected cases and rarely find time to discuss them with the consultant.

And how does the consultant update his own knowledge? It is entirely up to his own devices. Flooded with advertisements for courses either from the National Health Service Training Authority, British Institute of Mental Handicap, the Association for Psychological Therapies and the Institute of Organisation and Social Studies, the consultant makes his choice. What benefit he gets out of these 
courses, when he attends, is another matter. No doubt, most of these courses spare him from the drudgery of Joint Planning Meetings. Useful but limited are the College Meetings, especially the Sub-Speciality Groups.

When it comes to research, it is a question of 'the mind willing, and the body weak'. After a day's duties in two hospitals and hostels, as far apart as 18 miles, and meetings with statutory and non-statutory oganisations, the consultant exhausts his ability for more work. Prospective or retrospective research demands a lot of energy, patience and time. The absence of technicians or junior doctors to help collect data is a further, and demoralising, disadvantage.

Managerially, is the consultant in mental handicap involved? The experience varies. Some are 'at the deep end'; the majority, disengaged or even alienated. One consultant, for example, on his first appointment, became a member of the Unit Management Group, a member of the Advisory Sub-Committee in his Region, and an adviser to the Region on the approval of doctors for purposes of Section 12 of the 1983 Mental Health Act. Budgets for drugs, medical personnel, medical and surgical equipment were transferred to him. Requests for his items for revenue expenditure, and his comments on the Strategic Plan, followed. For a senior registrar, coming to his first consultant appointment, from a university hospital, the task was daunting. He had not been prepared for the management roles facing him.

But such stories are few. Most consultants in mental handicap get to hear of the contents of strategic or community care plans in the corridors of administration blocks, or even on the wards. There is a case of a consultant who, when told on a ward round that the ward was to close, took the story for gossip. Two weeks later, first thing on a Monday morning, his secretary asked him if he knew that patients on that particular ward had been discharged over the weekend and that the ward had been closed. Two months later, still 'bowled over', he re-admitted two of the discharged clients, at the request of a harassed general practitioner. Some senior consultants, or superintendents with nurses or psychologists as their new Unit General Manager, are the most alienated.

Wouldn't you think that the practice of the psychiatry of mental handicap, his speciality, would be the least of the consultant's problems? You would be wrong; for there too, there are snags. Where, for example, will the consultant best treat mentally handicapped people with mental illness? A consultant, for example, advocated the use of a six-bedded unit for the short-term treatment of mentally handicapped people when they become mentally ill. The proposal touched a 'sore spot' in some members of the multi-disciplinary team. "We are not trained in mental illness. The mentally handicapped should use the same mental illness units as others. We are referring this matter to our trade union," the nurses retorted. The consultant sampled the opinion of nurses in a nearby mental illness unit. "We are not trained in mental handicap," came their reply. The senior nurses added, "you will need an injection of funds to recruit nurses trained in both mental handicap and mental illness." To date, the consultant continues treating mentally ill, handicapped persons wherever he can find an empty bed. The special need of these clients is then secondary to the availability of beds. Many consultants in the mental handicap service have a similar problem.

The Regional Policy on this issue looks simplistic: that mentally handicapped persons with mental illness should be treated in psychiatric units like every other person. Were general psychiatrists and other medical and paramedical staff consulted before the Policy was drawn up? Beds are at a premium these days; would the general psychiatrist spare one or two of them for the use of another consultant? Or, will it be a question of "I will admit and treat him as soon as a bed becomes available."? Before this last concession, however, the generalist makes sure that the patient can give some history and is adequate in his self-care skills. If the patient is mildly or severely mentally handicapped-no deals. Each failed negotiation, repeated, dents the ego, or the selfesteem of the consultant in mental handicap. To compound matters, it is not unusual for the generalist to re-refer his select group for day placement to the consultant in mental handicap. Knowing, as the consultant in mental handicap does, what little placement options there are for this minority group, hospitalisation and drug treatment at the acute stage seem the easiest slot in the whole treatment package. That is, if the setting is right.

If the setting for the practice of the psychiatry of mental handicap is in question, the quality of the current practice is not. Undeniably, it is bad.

Registered nurses in mental handicap are hard to come by. Nurses registered in both mental handicap and mental illness are a rarity. Spoilt with opportunities for promotion to senior posts, the registered nurses in mental handicap do not see the need for further training in mental illness. Arguably, their present nursing officers were not trained in both mental handicap and mental illness. The result: mentally ill clients are admitted to the care of nursing staff with no experience in the care of the mentally ill and who do not want to know. A mentally ill patient showing symptoms of drug-induced dystonia passes as attention seeking. A request for the monitoring of biological signs is seen as another addition to the workload. Equally problematic is the after-care of these patients when discharged.

Consultant jobs in mental handicap need 'pepping up' if they are not to become 'dead end' posts. 
The post and the service need the following changes to invigorate them:

(1) The consultant in mental handicap is first and foremost a psychiatrist, and should be seen to be practising the psychiatry of mental handicap. For this, a convenient setting is inevitable. Beds in a mental illness unit bring the consultant closer to his other psychiatric colleagues. To this local peer group support add, to the benefit of the client, closer liaison psychiatry. A psychiatric unit within the mental handicap service is a good alternative. It still leaves the consultant isolated.

(2) In whatever setting, trained nurses in mental handicap and illness will be needed for both the hospital and the community services. This necessitates more resource allocation.

(3) Admission policies to hospitals should be reviewed. At present all persons admitted, even for social reasons, come under the umbrella of the consultant. Because they have no medical or psychiatric needs, some respite care clients are not seen by a doctor, especially if admitted on a Friday and discharged the following Monday. Yet, in the case of an accident, the consultant can be held to account.
(4) At the Regional level, peer group reviews should be encouraged. With regular meetings, consultants can discuss and pilot multi-centre research.

(5) Trainee psychiatrists in teaching hospitals need to spend some months in a mental handicap service in non-teaching hospitals. Then they will be exposed to the clinical and administrative problems peculiar to such hospitals. Should the trainee choose to work in a non-teaching hospital, the experience can be priceless.

(6) Becoming less parochial, the university teaching centres can allow lecturers a few teaching sessions outside their district. So should the trainee psychiatrists in districts outside these teaching centres be allowed training periods in the teaching centres?

What of consultants in such non-teaching centres contributing to seminars in the teaching centres?

Mental handicap is no longer a place where retired consultant psychiatrists return to avoid the boredom of inactivity. But it could well be where bored psychiatrists sit on the job, earning a living. It need not be. 